\title{
Análise das políticas públicas de prevenção e promoção em saúde sob um olhar foucaultiano
}

\author{
Análisis de las políticas públicas de prevención y promoción en salud bajo una mirada \\ Foucaultiana. \\ Analyzes of Prevention and Health Promotion Policies under Foucault's View
}

\author{
Laíza Piva Mázaro \\ Universidade Católica Dom Bosco, Campo Grande, MS, Brasil. \\ Anita Guazzelli Bernardes \\ Universidade Católica Dom Bosco, Campo Grande, MS, Brasil.
}

\section{Angela Elizabeth Lapa Coêlho}

Centro Universitário de João Pessoa, João Pessoa, PB, Brasil.

\section{Resumo}

Este artigo analisa as Políticas públicas de Saúde relacionadas à Prevenção de Doenças e à Promoção da Saúde, em vigor no Brasil, referentes à população em geral. Além disso, compara tais políticas com os indicadores de saúde do Estado de Mato Grosso do Sul e do município de Campo Grande. O objetivo do estudo é analisar esses documentos como formas de objetivação e de subjetivação dos indivíduos que convivem com estas leis. A análise foi feita por meio das ferramentas conceituais de Foucault sobre verdade, poder e governamentalidade, entre outras. Compreende-se, a partir desta pesquisa, que as políticas públicas são mecanismos de poder que buscam controlar a população, caracterizando-se como formas de governamentalidade e de biopoder que se dão como tecnologias de biopoder, estratégias que caracterizam o investimento na vida, ou seja, bio-regulação da população, mecanismo que produz investimento no fazer viver ou no deixar morrer.

Palavras-chave: Políticas Públicas, Saber, Poder, Biopoder, Governamentalidade.

\section{Resumen}

Este artículo analiza las políticas públicas de la salud relacionadas a la prevención de enfermedades y a la promoción de la salud, en vigor en Brasil, relativas a poplación en general. Además, compara estas políticas con los indicadores de salud del estado de Mato 
Grosso do Sul y el Municipio de Campo Grande. El objetivo del estudo es analizar eses documentos como formas de objetivación y de subjetivación de los individuos que viven con estas leyes. El análisis fue hecho por medio de herramientas conceptuales de Foucault sobre verdad, el poder y la gobernabilidad, entre otras. Se entiende de esta investigación que las políticas públicas son mecanismos de poder que tratan de controlar a la población, caracterizadas como una forma de gubernamentalidad y del biopoder que se presentan como tecnologías de biopoder, estrategias que caracterizan la inversión en la vida, es decir, la bioregulación de la población, un mecanismo que produce la inversión en el hacer vivir o en el dejar morir.

Palabras-clave: políticas públicas, conocimiento, poder, biopoder, gubernamentalidad.

\begin{abstract}
This article analyzes public health policies related to disease prevention and health promotion directed towards the general population that are currently in force in Brazil. Besides, it compares these policies with health indicators both in the state of Mato Grosso do Sul, and in the city of Campo Grande. The objective of this study is to analyze this docments as forms of objectivation and subjecttivation of people that live under these laws. The analysis has been grounded on Foucault's conceptual tools of truth, power, and governmentality, among others. From this research, it is possible to understand that public policies are power devices that aim to control the population, and are thus characterized as forms of governmentality and biopower which occur as bio-power technologies, i.e. strategies that characterizethe investment in life, that is, the bio-regulation of the population, as a mechanism that produces investment in either living or letting die.
\end{abstract}

Keywords: Public Policies, Knowledge, Power, Bio-Power, Governmentality.

\title{
Introdução
}

Este artigo tem como objetivo analisar as políticas públicas de saúde voltadas para prevenção de doenças e promoção da saúde, bem como os indicadores de saúde do Estado de Mato Grosso do Sul e da cidade de Campo Grande, utilizando para tal reflexão as ferramentas conceituais foucaultianas de verdade e poder.

Os dados foram coletados por meio de pesquisas via internet e visitas à Secretaria Estadual de Saúde de Mato Grosso do Sul e à Secretaria Municipal de Saúde de Campo Grande, nesta cidade, no ano de 2009. Foram coletados apenas 
dados referentes às políticas que tratassem de alguma estratégia de prevenção de doenças ou de promoção de saúde e que estivessem sendo colocadas em prática nessa localidade.

Tal pesquisa deve-se à necessidade de conhecer as Políticas Públicas em saúde no Brasil e colocá-las em análise no que tange às formas de objetivação que produzem, ou seja, considerando que sujeitos e formas de cuidado são constituídos mediante tais Políticas Públicas e indicadores de saúde.

\section{As Políticas Públicas de Prevenção e}

Promoção

O processo da reforma sanitária iniciado na década de 1970 começa a tomar forma como política pública a partir de 1986, data da VIII Conferência Nacional de Saúde. A VIII Conferência Nacional de Saúde traçará os princípios tanto doutrinários quanto organizativos do novo sistema de saúde no Brasil, instituídos na Constituição de 1988, na formulação do Sistema Único de Saúde (SUS). A ampliação do conceito de saúde implicará a modificação das formas de atenção. A atenção à saúde não será mais restrita à cura e à reabilitação, na medida em que será expandida para níveis de prevenção de doenças e outros agravos e promoção de saúde. Isso significará uma focalização no âmbito do cuidado que diz respeito à atenção básica, à estratégia de saúde da família, aos sistemas de referências das comunidades assistidas e à educação em saúde (Czeresnia, 2003).

A prevenção subentende uma ação antecipada que impede que as doenças se manifestem ou se agravem, baseada na análise dos indicares de risco e vulnerabilidade por meio de estudos epidemiológicos e de um mapeamento da região e das características da população dessa localidade. Também prevê a realização de vigilância no sentido de perceber enfermidades segundo a sua periculosidade e controlar os seus agravos, a fim de evitar sua transmissão e o surgimento de epidemias. Como prevenção também se entende as ações educativas tais como campanhas para informação e conscientização da população acerca das doenças, de maneira a promover mudança de hábitos cotidianos através de recomendações normativas em relação às suas atividades. A prevenção é caracterizada por um trabalho realizado por profissionais de saúde e direcionada a grupos considerados de risco (Czeresnia, 2003).

A promoção da saúde compreende ações de abertura de possibilidades, de fomento e impulso à vida. Não é dirigida à doença ou a grupos de risco, é extensiva a toda a população e busca aumentar a saúde 
em sua positividade. Busca o fortalecimento da capacidade individual e coletiva de lidar com os múltiplos fatores condicionantes da saúde, focalizando a compreensão de como as pessoas se relacionam com seu corpo e sua vida. Seu objetivo é incentivar a autonomia e a vitalidade. São princípios de sensibilização que incluem toda a comunidade, e não somente os profissionais de saúde ou do governo (Czeresnia, 2003).

A promoção de saúde diz respeito a dar impulso, a fomentar, não se dirigindo a uma determinada doença/desordem, mas ao aumento de potenciais de saúde. Essa lógica organiza-se a partir da Carta de Ottawa (1986), que passa a falar de saúde em sua positividade, ou seja, uma noção que se confunde com a própria vida, na medida em que se refere ao fortalecimento da capacidade individual e coletiva de lidar com a multiplicidade dos fatores condicionantes da saúde. Nesse sentido, a promoção de saúde envolve escolhas, sendo da esfera do valor, e não do conhecimento médico/científico exclusivamente (Caponi, 2003).

A prevenção de doenças e a promoção de saúde passam a operar com a relação entre saúde e condições de vida, considerando-se saúde e doença como formas pelas quais a vida se manifesta. Isso implicará que prevenção e promoção se situam entre a subjetividade da experiência de saúde/doença e a objetividade dos conceitos que lhe dão sentido e formas de lidar com tal vivência (Czeresnia, 2003).

Porém, não podemos considerar que esta visão ampliada de saúde seja algo natural e permanente através dos tempos, antes, precisamos observar que é resultado de diversas discussões e lutas por imposição de sentidos. Devemos compreender que foi por meio de jogos de poder e saber que tais mudanças no conceito de saúde e nas ações em saúde puderam ocorrer - trata-se, assim, de uma construção histórica e social. Também não podemos perder de vista que essa mudança no conceito de saúde não causa modificações apenas no nível de práticas, trazendo também novas formas de objetivação e de subjetivação.

\section{Alguns Conceitos Norteadores}

Os conceitos foucaultianos de verdade e poder são fundamentais para compreender as Políticas Públicas de maneira geral e, em especial, neste caso, as referentes à saúde, na medida em que estas são estratégias de poder, de formas de governo, de relações de saber/poder.

Por verdade, entende-se um conjunto de procedimentos regulados para a produção, a lei, a repartição, a circulação 
e o funcionamento dos enunciados. Circularmente ligada a estratégias de poder, que a produzem e a apoiam, e a efeitos de poder que ela induz e a reproduzem, a verdade não existe fora de relações de poder ou sem as relações de poder. Cada sociedade tem seus regimes de verdade, e estes, ao mesmo tempo em que produzem regimes de poder, também são produzidos por eles (Foucault, 2001).

As relações de poder e verdade produzem marcas identitárias, marcas que dizem quem e como somos, os códigos sociais produzidos nas relações cotidianas. As relações de poder/verdade produzem o sujeito, mas este está sempre mudando, está sempre em vias de desfazer-se e tornar-se outro sujeito a partir de uma nova forma de subjetivação (Foucault, 2001).

Em determinado momento histórico, ocorre um acontecimento, isto é, surgem fenômenos micropolíticos que acabam por se correlacionar, em decorrência de conjunções sociais, econômicas e culturais e de movimentos das pessoas que provocam mudanças nas formas de saber e poder instituídas, causando uma descontinuidade, uma ruptura histórica. Desta forma, os acontecimentos ocorrem por meio de relações de saber e poder, um rearranjo de saberes já constituídos de maneira que estes já não são os mesmos e não produzem a mesma realidade. Tal acontecimento torna possível a formulação de conceitos e conhecimentos, e estes adquirem status de verdade por meio de relações de saber e poder. Esse acontecimento, que se caracteriza por jogos de força e por luta de imposição de sentidos, marca uma história e, ao mesmo tempo, a muda e a torna diferente. A história não é linear, contínua, progressiva; não é feita de evolução, e sim de rupturas, de acontecimentos que possibilitam tais mudanças.

As relações de poder funcionam segundo uma economia política, a qual consiste em procedimentos que permitem fazer circular os efeitos do poder de forma ao mesmo tempo contínua, ininterrupta, adaptada e "individualizada" em todo o corpo social.

$\mathrm{O}$ poder possui um mecanismo chamado de biopoder. O biopoder é o poder que investe na vida e que, segundo Foucault (1988, p. 150), visa a "produzir forças, fazê-las crescer e ordená-las, mais do que barrá-las, dobrá-las ou destruí-las. [...] um poder que gere a vida e se ordena em função de seus reclamos". Como diz Foucault (1988, p.151), “agora é sobre a vida e ao longo de todo o seu desenrolar que o poder estabelece seus pontos de fixação". A discussão do autor sobre o biopoder faz parte das análises empreendidas sobre o Estado moderno. Essas análises percorrem a emergência da 
articulação entre formas de governo, economia política, população e segurança, não exclusivamente como um problema de racismo do Estado, mas da política social econômica das racionalidades liberais e neoliberais (Foucault, 1999, 2008).

Quanto às formas de organização do biopoder, este pode ser entendido como anátomo-política e biopolítica, que, segundo Foucault (1988, p.151), “... não são antitéticas, mas sim constituem dois pólos de desenvolvimento interligados por todo um feixe intermediário de relações de poder". As tecnologias disciplinares agem nos mecanismos que controlam os movimentos dos corpos. São anátomopolíticas, pois voltam-se para o funcionamento do corpo-organismo, da relação entre os órgão e suas funções, por exemplo, como produzir um certo movimento dos braços que permite acelerar o processo de produção de um artefato. A disciplina da anátomo-política permite o controle do espaço mediante o movimento e disposição dos corpos neste espaço, de modo a permitir maior vigilância e maior otimização dos processos de produção.

A anátomo-política visa ao indivíduo e age no corpo, que é entendido como máquina. A biopolítica visa à espécie humana, à população, e é uma tecnologia de poder que objetiva regular a vida cotidiana. O biopoder contempla tanto a anátomo-política quanto a biopolítica, sendo um conjunto de estratégias que visam à vida, ao seu controle $\mathrm{e}$ regulamentação em termos individuais e coletivos. Ele visa ao coletivo e à produção de formas de vida (Foucault, 2001).

Porém, o biopoder também pode ser utilizado como ferramenta do racismo de Estado, pois, ao priorizar a vida e o seu controle, regulamenta que haja ações que, quando executadas, podem causar danos a alguns para garantir a vida e a continuação da espécie, justificando, assim práticas eugenistas (Foucault, 2001). Sobre isso, Foucault (1988, p.154) escreve: “os rudimentos de anátomo e biopolítica, sendo técnicas de poder presentes em todos os níveis sociais e utilizadas por instituições diversas, operam também como fatores de segregação e de hierarquização social, garantindo as relações de dominação e efeitos de hegemonia". As Políticas Públicas caracterizam-se por mecanismos de biopoder, os quais focalizam a defesa da vida, valendo-se de formas de controle, regulação e organização tanto das populações quanto dos corpos.

Nas formas de governo de Estado Nação, o objetivo principal é proteger a sociedade, defender a nação; para isso, são instituídas leis e Políticas Públicas que visam a regulamentar, organizar a vida em sociedade, determinando direitos e deveres 
para os cidadãos, sendo que tais leis são operacionalizadas e fiscalizadas pelo Estado. Da mesma maneira, as políticas públicas têm como finalidade proteger a população e, por isso, caracterizam-se como estratégias de poder.

A racionalidade das formas de governo do Estado moderno não tem o objetivo de salvar a todos e preservar o bem comum ou de considerar o território como o principal foco de atenção, deixando as pessoas em segundo plano e vendo-as separadas do território e entre si. Para o Estado moderno, a arte de governar visa a governar as coisas, a relação entre as coisas e entre os homens e as coisas, os hábitos, as formas de agir e de pensar; assim, o território e as propriedades tornam-se variáveis secundárias, buscandose uma maneira correta de dispor as coisas para conduzi-las a um determinado fim: a regulação da sociedade como modo de operacionalização da política econômica (Foucault, 2008). Da mesma forma, as Políticas Públicas consistem em formas de governamentalidade, pois visam a regulamentar a relação das pessoas consigo mesmas e com as coisas, de maneira a atingir uma finalidade, que seria, por exemplo, evitar epidemias, controlar patologias ou melhorar a qualidade de vida das pessoas. As políticas públicas não são algo imposto às pessoas, sendo apresentadas à população como a melhor alternativa para garantir a sua saúde - com isso, os maiores beneficiados serão os próprios cidadãos que as colocarem em prática.

A governamentalidade, para Foucault (2001), inclui estratégias de poder que regem o governo de si e do outro, que mudam as formas de subjetivação dos indivíduos de acordo com as mudanças na organização social. Por meio de ações sobre outras ações possíveis, vão sendo modificadas as condutas, os conhecimentos, as informações, a maneira de se perceber e de se construir como sujeito.

Para Foucault (2001), existem dispositivos através dos quais o poder atua. O dispositivo sempre responde a uma urgência, algo que ocorre em um momento histórico e que cria a necessidade de um novo tipo de estratégia, é histórico e circunstancial. É uma estratégia de controle. É sempre um conjunto heterogêneo, uma rede de elementos, englobando discursos, instituições, arquitetura, leis, regulamentações, administrações, enunciados científicos, filosofia, moral e filantropia; é discursivo e não-discursivo e acontece num campo de luta por imposição de sentidos, através de relações de força. Dessa maneira, as Políticas Públicas são estratégias de poder, são dispositivos por meio dos quais o poder atua, pois compreendem ações 
capilarizadas que envolvem todas as pessoas. Não são ações decrescentes apenas e dependem da ação de cada indivíduo, inclusive consigo mesmo, para poderem acontecer. As formas de cuidado de si, como a forma de se alimentar, de cuidar da saúde ou mesmo de se perceber como indivíduo podem certamente se tornar formas de exercício do poder, pois manifestam o que é permitido ou não ser feito em relação ao próprio corpo e ao corpo do outro.

\section{Prevenção de Doenças e Promoção de}

Saúde segundo as ferramentas

\section{Foucaultianas}

A análise das Políticas Públicas é realizada por meio da compreensão das relações de saber, poder, formas de subjetivação produzidas pelas políticas de prevenção de doenças e promoção da saúde, além da análise e comparação entre estas e os indicadores de saúde. Os dados são referentes às políticas colocadas em prática no Estado de Mato Grosso do Sul e no município de Campo Grande no ano de 2009, mais especificamente, as políticas de Prevenção e Controle de Epidemias de Dengue, de Prevenção de Impacto da Violência na Saúde das Crianças e Adolescentes e a Política Nacional de Promoção da Saúde. Elas foram escolhidas em virtude da grande incidência no Brasil de episódios violentos contra crianças e adolescentes e pelo fato de o Estado de Mato Grosso do Sul enfrentar epidemias graves de dengue quase todos os anos. Segundo dados do Ministério da Saúde, em 2009 foram registrados 51.873 casos de dengue em todo o Brasil. Apenas cinco municípios - Campo Grande (MS), Goiânia (GO), Aparecida de Goiânia (GO), Rio Branco (AC) e Porto Velho (RO) apresentaram mais de $30 \%$ dos casos de dengue, mostrando que o agravamento da doença está se dando no Centro-Oeste.

A violência doméstica, a qual as crianças e adolescentes estão mais expostos, pode ser compreendida como violência física, psicológica, sexual e negligência. Os casos que mais são denunciados estão relacionados à violência física, que muitas vezes é aceita pelos pais como método educativo. As estatísticas em relação à violência de qualquer natureza contra as crianças e os adolescentes são fragilizadas em virtude da subnotificação dos casos. Segundo dados do Datasus de 2006 (Ministério da Saúde, 2010), no município de Campo Grande, 25\% das mortes apresentam causas externas. Essas causas externas são caracterizadas como aquelas que não apresentaram uma justificativa específica para o óbito, porém, podem relacionar-se a situações de violência não diagnosticadas. Essas causas externas são responsáveis por 25 (a cada 
cem mil habitantes) para crianças de 0 a 9 anos, 12 para crianças de 10 a 14 anos e 50 para adolescentes de 15 a 19 anos, sem discriminação segundo o sexo. Segundo estatísticas, no município de Campo Grande, em 2007, houve 237 óbitos relacionados a causas externas, especificamente causadas por agressões, dentre as quais, 50 mortes de adolescentes entre 15 e 19 anos e três mortes de adolescentes de 10 a 14 anos (Ministério da Saúde, 2010). Dessa forma, a violência de qualquer natureza contra as crianças e os adolescentes, principalmente a violência sexual, apesar de não ter números reais e sim aproximados, é um quadro mais frequente do que se imagina na realidade de todo o país.

Pelo fato de todas as Políticas colocadas em prática tanto no Estado de Mato Grosso do Sul quanto no município de Campo Grande se originarem da esfera do governo federal, foi feita a análise das Políticas Nacionais que estão sendo operacionalizadas no âmbito estadual e municipal ligadas aos indicadores de saúde da região, mas que, de maneira geral, abrangem toda a população brasileira, atingindo em específico a população do Estado e do município que foram pesquisados.

Após a identificação das políticas e compreensão dos indicadores de saúde relativos a esta região, foi realizada a análise seguindo-se a proposição de Foucault (2000, p.122):

\footnotetext{
em vez de dar um sentido a essas unidades, coloca-as em relação com um campo de objetos; em vez de lhes conferir um sujeito, abre-lhes um conjunto de posições subjetivas possíveis; em vez de lhes fixar limites, coloca-as em um domínio de coordenação e de coexistência; em vez de lhes determinar a identidade, aloja-as em um espaço em que são consideradas, utilizadas e repetidas.
}

Desta maneira, as ferramentas foucaultianas orientam a forma de pesquisa a ser realizada, pois se deve, de acordo com essas trilhas investigativas, observar não o que é o acontecimento em si, mas perceber quais condições sociais, históricas e políticas permitiram que tal realidade se constituísse da maneira como está, e o mais importante, perceber como tal realidade se manifesta na história, na literatura e na vida das pessoas.

\section{As Estratégias para Prevenção e Promoção na Saúde}

A Política de Prevenção e Controle das Epidemias de Dengue determina uma série de condutas consideradas adequadas à população e prevê que, se as pessoas as executarem, gerarão certos resultados desejados, como evitar uma epidemia ou 
diminuir os casos de dengue. A lei determina como função dos Agentes Comunitários de Saúde (ACSs) "orientar e acompanhar o morador na remoção, destruição ou vedação de objetos que possam se transformar em criadouros de mosquitos, removendo mecanicamente, se necessário, as formas imaturas do mosquito; estimular os moradores a assumirem o compromisso com a adoção das ações de prevenção, de forma espontânea e rotineira” (Brasil, 2009). A dengue é considerada uma epidemia, na realidade, com características endêmicas e que é alvo de Políticas Públicas de Prevenção específicas. Tais Políticas Públicas de vigilância e prevenção da dengue operam no cotidiano das pessoas e das comunidades, principalmente as que vivem em regiões menos privilegiadas.

Os ACSs tornam-se uma estratégia de controle da forma como a comunidade vive, de seus hábitos cotidianos e do modo de adoção de novos comportamentos, fazendo parte de um dispositivo de governo da população.

Há determinações de como a equipe de saúde deve agir em situações epidêmicas ou não-epidêmicas, bem como sobre ações de assistência, vigilância epidemiológica, controle vetorial e mobilização e comunicação, por exemplo, "quando houver suspeita de dengue identificada em visita domiciliar, as pessoas já devem ser orientadas quanto à hidratação oral pelo ACS ou pela equipe de saúde da família e encaminhadas à unidade de saúde mais próxima” (Brasil, 2009).

Não se trata de ações violentas, que submetem a todos e os obrigam a assumir certos comportamentos; são ações que dão possibilidade de escolher fazer ou não, são ações sobre ações possíveis que caracterizam certa forma de governo da população como espécie. Trata-se de estratégias dirigidas ao conjunto da comunidade que marcam de determinada forma essa comunidade/população destinatária das políticas, pois cabe a esses grupos considerados vulneráveis, em zonas de risco, modificarem e adotarem outras formas de viver. Porém, como há um discurso científico, um regime de verdade que pauta tais determinações e que indica que, se a população as realizar, uma epidemia não irá acontecer ou será minimizada, as pessoas são, de certa forma, impelidas a cumprir o que é estabelecido. Para Foucault (2001, p.13),

\footnotetext{
[... ] a "verdade" é centrada na forma do discurso científico e nas instituições que o produzem; está submetida a uma constante incitação econômica e política; é objeto, de várias formas, de uma imensa difusão e de um imenso consumo; é produzida e transmitida sob o controle, não exclusivo, mas dominante, de alguns grandes aparelhos políticos ou econômicos
} 
(universidade, exército, escritura, meios de comunicação); enfim, é objeto de debate político e de confronto social (as lutas "ideológicas").

Assim, tais leis produzem novas formas de subjetivação, mudando a forma como as pessoas lidam com o lixo, com os objetos que podem acumular água em suas casas, daí surgindo novos comportamentos e ações.

A prevenção supõe medidas antecipadas para evitar adoecimentos ou agravos, por meio de ações que controlem e modifiquem o comportamento da população em relação a determinadas possibilidades de adoecimento. Trata-se, portanto, de formas de manifestação do biopoder, que se propõe a defender a vida e a investir para que ela seja melhorada, como é o caso das Políticas Públicas de Prevenção de Impacto da Violência na Saúde das Crianças e Adolescentes (2009), a Política de Prevenção e Controle de Epidemias de Dengue (2009), a Política de Prevenção e Controle da Hanseníase (1976), o Pacto pela Saúde no Brasil (2004), a Política de Vigilância em Saúde Ambiental (2005) e a NOB-SUS 01/96, dentre tantas outras.

As Políticas de Prevenção ainda mantêm um caráter disciplinar, pontuando etapas, ciclos, espaços e comportamentos adequados, metas a cumprir; elas visam a alcançar os objetivos a partir da mudança de conduta da população e de seu controle. Podemos ver um exemplo disso na Cartilha para a Prevenção do Impacto da Violência na Saúde das Crianças e Adolescentes, no que diz respeito as estratégias para a sua implementação:

$$
\begin{aligned}
& \text { específicas; realização de campanhas para } \\
& \text { mobilização e sensibilização; elaboração } \\
& \text { de diretrizes, parâmetros e metodologias; } \\
& \text { elaboração de normas técnicas capacitação } \\
& \text { de profissionais e elaboração de material } \\
& \text { educativo; estruturação e qualificação da } \\
& \text { Rede de Atenção à Saúde; construção de } \\
& \text { indicadores de desenvolvimento e } \\
& \text { instrumentos de acompanhamento e } \\
& \text { avaliação; fomento à pesquisa na área; } \\
& \text { articulação entre os diversos ministérios, } \\
& \text { secretarias e órgãos relacionados" (Brasil, } \\
& \text { 2009, p.08). }
\end{aligned}
$$

Da mesma maneira, as Políticas de Promoção da Saúde, mesmo que não se dirijam a populações específicas, também estabelecem metas. São formas disciplinares de controlar a população, como a Política Nacional de Promoção da Saúde (portaria $n^{\circ} 687$ de 2006), que tem como objetivo "promover a qualidade de vida e reduzir vulnerabilidade e riscos à saúde relacionados aos seus determinantes e condicionantes - modos de viver, condições de trabalho, habitação, ambiente, educação, lazer, cultura, acesso a 
bens e serviços essenciais" (Brasil, 2006, p.19).

As Políticas Públicas também podem ser compreendidas como estratégias de biopoder que visam ao bem e ao controle da população, pelo seu desenvolvimento e prosperidade. São tanto anátomo quanto biopolítica, pois visam ao corpo de forma individual e à população em geral, como podemos ver na Política de Prevenção de Impacto da Violência na Saúde das Crianças e Adolescentes (Brasil, 2009, p.7), quando diz das responsabilidades das esferas de governo: "acompanhamento das vítimas e das famílias com visitas sistemáticas de profissionais de saúde para identificar as situações de violência (maus-tratos, negligência, exploração sexual, abuso sexual, trabalho infantil, entre outros) ou de violência repetida". Essas políticas priorizam a vida e prevêem tanto ações para a recuperação das pessoas vítimas de violência, de forma individual, quanto ações educativas e de conscientização e mobilização comunitária. As determinações das políticas são ferramentas de biopoder, como explica Foucault (1988, p.152) quando diz que “aparecem no terreno das práticas políticas e observações econômicas, dos problemas de natalidade, longevidade, saúde pública, habitação e migração, técnicas diversas e numerosas para obterem a sujeição dos corpos e o controle das populações". Sendo assim, as Políticas Públicas têm forte impacto sobre a vida cotidiana das pessoas, construindo novas formas de agir, de ser e de compreender a vida. Trazem mudanças também na maneira do sujeito se entender como indivíduo e como cidadão que faz parte de uma sociedade específica e que deve agir de forma adequada para não prejudicar nem a si, nem aos outros com quem convive.

As Políticas Públicas de prevenção de doenças e as de promoção da saúde são como define Foucault (1988) formas de regulação de populações: a demografia, a estimativa da relação entre recursos e habitantes, a tabulação das riquezas e de sua circulação, a estimativa das vidas com sua duração provável. Essas políticas são elaboradas com base nos indicadores de saúde da população, como na Política Nacional de Promoção da Saúde, que traça como ações específicas a serem realizadas, claramente baseadas nos indicadores de saúde do país, a "Divulgação e implementação da Política Nacional de Promoção da Saúde; Alimentação saudável; Prática corporal/atividade física; Prevenção e controle do tabagismo; Redução da morbimortalidade em decorrência do uso abusivo de álcool e outras drogas; Redução da morbimortalidade por acidentes de trânsito; Prevenção da violência e estímulo 
à cultura de paz; Promoção do desenvolvimento sustentável" (Brasil, 2006, p.27).

Quanto aos indicadores, tanto demográficos, quanto socioeconômicos e de mortalidade, os dados (Ministério da Saúde/Datasus) apresentam que a qualidade de vida e o índice de saúde da população vem aumentando de forma constante. Porém, devemos perceber que o fato de existirem determinados indicadores sendo investigados provoca a existência de uma nova conformação da população e sobre os fatores que estarão sendo investigados. Quando falamos de indicadores de mortalidade e natalidade, assumimos uma determinada visão sobre morte e vida. Também na maneira como a população é dividida, para fins de construir indicadores de saúde, são formadas categorias, utilizados critérios como o de risco, vulnerabilidade, situação socioeconômica, nível de instrução/escolarização. Isso leva a compreensão das formas de manifestação do biopoder, que, por sua vez, são produzidas por relações de saber que fazem com que determinados grupos estejam mais em evidência do que outros. Esta relação fica clara ao observarmos como muda a nossa forma de ver as pessoas com hanseníase quando entra em vigor a Política de Prevenção e Controle de Hanseníase (Ministério da Saúde, 1976), a qual inclui a informação da população em geral sobre os sintomas, formas de tratamento e, principalmente, de prevenção, dentre outros tantos casos.

Sobre o surgimento da população como um problema de saúde e como uma preocupação do Estado, tendo como estratégia a utilização de métodos estatísticos - o que hoje conhecemos como indicadores de saúde -, Foucault (2001, p. 82) diz:

\footnotetext{
Desde o final do século XVI e começo do século XVII [...] se estabelecem estatísticas de nascimento e mortalidade e, na Inglaterra as grandes contabilidades de população aparecem no século XVII. Mas, tanto na França quanto na Inglaterra, a única preocupação sanitária do Estado foi o estabelecimento dessas tabelas de natalidade e mortalidade, índice da saúde da população e da preocupação em aumentar a população, sem, entretanto, nenhuma intervenção efetiva ou organizada para elevar o seu nível de saúde.
}

Dessa maneira, passa-se a controlar a população, mas visando à sua força e produtividade, e não necessariamente a sua saúde. No início, o controle dá-se sob forma de quarentenas; em seguida, surge o modelo de atenção à saúde por exclusão, passando depois para outros tipos de atenção até chegar hoje às ações preventivas. Hoje, os indicadores de saúde, 
elaborados pelo Ministério da Saúde, funcionam da mesma maneira. Eles são utilizados para o controle da população e de suas condições de saúde, como aparece na Política Nacional de Promoção da Saúde, que diz:

no SUS, a estratégia de promoção da saúde é retomada como uma possibilidade de enfocar os aspectos que determinam o processo saúde-adoecimento em nosso País - como, por exemplo: violência, desemprego, subemprego, falta de saneamento básico, habitação inadequada e/ou ausente, dificuldade de acesso à educação, fome, urbanização desordenada, qualidade do ar e da água ameaçada e deteriorada” (Brasil, 2006, p.14).

Assim, os indicadores potencializam formas mais amplas de intervir em saúde. No entanto, como explica Foucault (2001, p.84), agora o esquadrinhamento é feito por órgãos específicos,

uma organização administrativa para controlar a atividade dos médicos. [...] ao nível do Ministério ou da administração central, um departamento especializado é encarregado de acumular as informações que os médicos transmitem, ver como é realizado o esquadrinhamento médico da população, verificar que tratamentos são dispensados, se reage ao aparecimento de uma doença epidêmica, etc., e, finalmente, emitir ordens em função dessas informações centralizadas.

Os indicadores de saúde são formas de objetivação de estratégias de poder/saber utilizadas para controlar a população, mas, principalmente, são formas de subjetivação e de objetivação.

São formas de objetivação, pois, na medida em que são criadas categorias de investigação e controle dentro da população, de modo a segmentar, esquadrinhar, qualificar segundo determinados critérios, como o de mortalidade, idade, grupo de risco, etc., também são criadas novas figuras, novos objetos. Por exemplo, quando são obtidos os indicadores de que há grande mortalidade infantil, são elaborados conhecimentos por meio de pesquisa para compreender quais as causas, os fatores desencadeantes e mantenedores deste fenômeno; então são criadas estratégias de ação para reduzir tais indicadores, o que podemos considerar como as Políticas Públicas em Saúde. Porém, não são criadas apenas leis ou conhecimentos específicos, mas, no momento em que a problemática das crianças é colocada em discurso, é criada uma conformação de criança, uma criança que precisa ser cuidada, alimentada e protegida pelo Estado e pela família para que possa sobreviver. Isso pode ser mais bem explicado com o que Foucault (2001) 
diz: quando um objeto é nomeado e dotado de sentido, ele não é apenas nomeado. Sendo assim, o ato de dar sentido a algo é um ato de criação do mesmo, e, ao receber um nome, o objeto adquire também existência e realidade.

Ao mesmo tempo, os indicadores de saúde são produtores de formas de subjetivação, pois, como já foi dito, é a partir deles que são elaboradas as Políticas Públicas - eles direcionam as ações em saúde. Em consequência disso, as pessoas passam a adquirir novos hábitos, novos comportamentos, posturas diferentes em virtude do que a política determina que deve ou não ser realizado. Portanto, os indivíduos vão se tornando novas pessoas, vão se subjetivando a partir dessas políticas, dessas relações de poder/saber.

Como diz Foucault (2001), o modelo de arquitetura desenvolvido por Bentham e conhecido por panóptico, permitiria exercer de forma boa e fácil o poder, exercendo um controle físico sobre as pessoas, que estariam sob constante vigilância. Porém, com o passar do tempo, os próprios indivíduos passam a se controlar; em virtude de saberem que estão sendo observados, modificam o seu comportamento. No panóptico, "cada camarada torna-se um vigia" (Foucault, 2001, p.215). Existe algo que Foucault (2001) chama de poder omnividente caracterizado por haver vigilância não só dos guardas sobre os presos, mas dos presos sobre os presos e de cada um sobre si mesmo. Este trecho nos esclarece tal aspecto: "seu problema não era fazer com que as pessoas fossem punidas, mas que nem pudessem agir mal, de tanto que se sentiriam mergulhadas, imersas em um campo de visibilidade total em que a opinião dos outros, o olhar dos outros, o discurso dos outros os impediria de fazer o mal ou o nocivo" (Foucault, 2001, p.215).

Da mesma maneira, as Políticas Públicas agem como o panóptico, criando nas pessoas a sensação de que estão sendo controladas e de que suas ações terão consequências não só para si. As próprias pessoas passam a se "policiar", passam a controlar suas ações e comportamentos para que não se sintam observadas, recriminadas ou em dívida para com o governo, para com as pessoas com quem convivem ou para consigo mesmas cuidando mais de seus quintais para evitar a dengue ou controlando sua forma de lidar com as crianças para que não haja algo que se caracterize como violência ou abuso, segundo o que a lei classifica. Os principais passos são conscientizar e mobilizar a população, sensibilizando-a para defender as crianças e adolescentes de situações de violência, e conversar com famílias, escolas, comunidade, serviços de saúde e outros setores da sociedade. 


\section{Considerações Finais}

Em seu texto sobre a Razão de Estado, Foucault (1996, p.318) diz que considera a subjetividade, a identidade e a individualidade como problemas sociais. "É perigoso, conforme penso, considerar a identidade e a subjetividade como componentes profundos e naturais, que não são determinados por fatores políticos e sociais". Portanto, devemos ter clareza de que todos os indivíduos são construídos pela sua cultura, por seu ambiente e pelas relações que estabelecem consigo, com as coisas e com os outros mediante relações de poder/saber.

Devemos compreender que as Políticas Públicas utilizadas pelo Estado Brasileiro como estratégias de prevenção de doenças e promoção da saúde são mecanismos de governamentalidade e de biopoder que visam melhorar a qualidade de vida da população e dos indivíduos. Segundo Foucault (1988, p.156), há uma grande "proliferação das tecnologias políticas que, a partir de então, vão investir sobre o corpo, a saúde, as maneiras de se alimentar e de morar, as condições de vida, todo o espaço da existência”, na forma que conhecemos hoje como Políticas Públicas. O investimento na vida da população no Brasil engendra-se de modo mais intenso a partir das reformas na saúde na década de 1970. Essa iniciativa se dá em razão de uma resposta política às questões sociais que se formulam pela reforma sanitária. A resposta começa a se organizar em termos de mecanismos de governamentalidade voltados para políticas sociais e não apenas para políticas econômicas. Entretanto, seguindo os rastros de Foucault (2008), caracteriza-se mais por uma política social econômica do que propriamente por uma política social, na medida em que a equalização das condições de acesso a possibilidades de vida torna-se um mecanismo antieconômico em uma racionalidade neoliberal.

Porém, não se trata mais de uma lei que se referia como em tempos medievais ao gládio, à morte, e sim de um poder que se encarrega da vida e utiliza mecanismos contínuos, reguladores e corretivos. Para Foucault (1988, p. 157), “um poder dessa natureza tem que qualificar, medir, avaliar, hierarquizar, operar distribuindo em torno da norma, com função estritamente reguladora”. Assim as Políticas Públicas, especialmente as relacionadas à prevenção de doenças e promoção da saúde, tratam-se de estratégias de governo para mapear, conhecer e controlar a população geral e sua maneira de viver.

Não se trata de discutir se as Políticas Públicas são boas ou ruins, ou se seus objetivos estão sendo alcançados com sucesso ou não, mas de fazer um estudo de sua genealogia, compreender que eventos, 
que acontecimentos fizeram com que elas existissem da forma como existem, o que aconteceu ou o que deixou de acontecer para que a saúde fosse vista dessa maneira. Ao considerar as Políticas Públicas como um mecanismo biopolítico das formas de governamentalidade, a genealogia encaminha a investigação para a análise do Estado moderno, fundamentalmente, quando a racionalidade liberal em um primeiro momento e neoliberal mais contemporaneamente, tornam o fazer viver ou o deixar morrer não um fenômeno natural, mas como aquilo que irá também constituir o próprio campo político, ou seja, são fenômenos que se localizam dentro e não fora do território da política (Foucault, 1999). Como diz Foucault, “a genealogia é cinza; ela é meticulosa e pacientemente documentária. Ela trabalha com pergaminhos embaralhados, riscados, várias vezes reescritos" (Foucault, 2001, p.15). Do mesmo modo, foi realizada esta pesquisa, investigando as diversas leis, normas e portarias do Ministério da Saúde e a forma como estas afetam as pessoas em sua vida cotidiana.

Além disso, é de grande importância que possamos compreender que as Políticas Públicas são fatores que constituem a forma como os sujeitos se constituem e como compreendem a si e ao mundo.
Porém, as mesmas políticas que são utilizadas para defender a vida podem, em determinados momentos e circunstâncias, tornar-se instrumentos eugênicos, ou seja, formas de racismo de Estado. Como demonstra Foucault, "o direito que é formulado como de vida e morte é, de fato, o direito de causar a morte ou de deixar viver" (Foucault, 1988, p.148). Dessa maneira, as instâncias de governo, na medida em que controlam a que população e em que quantidade se destinará o investimento em saúde (não só financeiro), podem fazer viver ou deixar morrer os grupos da forma que considerarem mais conveniente aos seus objetivos. Assim, como diz Foucault, “o princípio: poder matar para poder viver, que sustentava a tática dos combates, tornou-se princípio de estratégia entre Estados" (Foucault, 1988, p.149). As diferenças em termos de investimentos conformam-se, justamente, porque não é possível em uma racionalidade neoliberal o acesso igualitário às condições de vida, na medida em que a regulação econômica pressupõe mecanismos de concorrência através de oscilações e diferenças no campo social. Caso uma política social tivesse efetivamente um objetivo de diminuir ou mesmo acabar com as desigualdades isso invalidaria a própria política econômica. Neste caso, mantém-se um nível de investimento suficiente para minimizar os 
efeitos das desigualdades, porém não suficientes para modificar a lógica da própria governamentalidade neoliberal (Foucault, 2008).

Sendo assim, é extremamente importante observar e analisar as Políticas Públicas e a forma como são regulamentadas, para que os seus resultados não sejam o descaso e $\mathrm{o}$ descuido para com determinadas populações, como no caso de algumas etnias indígenas, populações ribeirinhas, moradores das favelas de grandes centros urbanos, populações carcerárias, enquanto se privilegiam outros grupos, tais como aqueles que apresentam condições individuais em termos de acesso a condições de vida - grupos com maior nível de escolarização, capacidade de investimentos nas carreiras pessoais.

\section{Referências}

Brasil (2006). Ministério da Saúde. Política

Nacional de Promoção da Saúde.

Brasília- DF.

Brasil (2004). Diário Oficial da União.

Portaria $\mathrm{n}^{\mathrm{o}} 1.172$, de 15 de junho de 2004. Seção $1, n^{\circ} 115$, de 17 de junho de 2004, p. 58-59.

Caponi, S. (2003) A saúde como abertura ao risco. Em: Czeresnia, D. Promoção de saúde: conceitos, reflexões, tendências. Rio de Janeiro:
Editora Fiocruz. p. 55 - 77.

Czeresnia, D. (2003) O conceito de saúde e a diferença entre prevenção e promoção. In Czeresnia, D. Promoção de saúde: conceitos, reflexões, tendências. Rio de Janeiro: editora Fiocruz. p. 39- 53.

Foucault, M. (1988) História da Sexualidade I: a vontade de saber. Tradução de Maria Thereza da Costa Albuquerque e J. A. Guilhom Albuquerque. Rio de Janeiro. Editora Graal.

Foucault, M. (1996) A Ordem do Discurso. São Paulo: Edições Loyola.

Foucault, M. (1999) Em defesa da sociedade. São Paulo: Martins Fontes.

Foucault, M. (2000) Arqueologia do saber. Rio de Janeiro: Forense Universitária.

Foucault, M. (2001) Microfísica do poder. $16^{a}$ ed. São Paulo: Graal.

Foucault, M. (2008) Nascimento da biopolítica. São Paulo: Martins Fontes.

Laíza Piva Mázaro. Universidade Católica Dom Bosco, Campo Grande, MS, Brasil.

E-mail: laizapiva@hotmail.com

Anita Guazzelli Bernardes. Possui graduação em Psicologia pela 
Universidade do Vale do Rio dos Sinos (1996), mestrado em Psicologia pela Pontifícia Universidade Católica do Rio Grande do Sul (2002) e doutorado em Psicologia pela Pontifícia Universidade Católica do Rio Grande do Sul (2006). Atualmente é professora e pesquisadora do Mestrado em Psicologia da Saúde da Universidade Católica Dom Bosco. Tem experiência na área de Psicologia Social e Saúde, com ênfase principalmente nos seguintes temas: políticas públicas, formas de subjetivação, psicologia e trabalho.

E-mail: anitabernardes@ig.com.br

\section{Angela Elizabeth Lapa Coêlho}

Doutorado em Psicologia Social pela University of Manitoba, Canadá(2000) Professora do Centro Universitário de João Pessoa, Brasil.

E-mail:coelho.angela1@gmail.com 